\title{
Streptococcus pyogenes protein $F$ promotes invasion of HeLa cells
}

\author{
Nobuhiko Okada, ${ }^{1}+$ Ichiro Tatsuno, ${ }^{1}$ Emanuel Hanski, ${ }^{2}$ Michael Caparon ${ }^{3}$ \\ and Chihiro Sasakawa'
}

Author for correspondence: Nobuhiko Okada. Tel: +8135791 6256. Fax: +81334444831 .
e-mail: okadan@platinum.pharm.kitasato-u.ac.jp

\author{
1 Department of \\ Bacteriology, Institute of \\ Medical Science, University \\ of Tokyo, Tokyo 108, \\ Japan \\ 2 Department of Clinical \\ Microbiology, The Hebrew \\ University Hadassah \\ Medical School, Jerusalem \\ 91010, Israel \\ 3 Department of Molecular \\ Microbiology, Washington \\ University School of \\ Medicine, St Louis, MO \\ 63110, USA
}

\begin{abstract}
Although the Gram-positive bacterium Streptococcus pyogenes (group A streptococcus) has been considered an extracellular pathogen which adheres to human mucosal epithelium, the streptococcus possesses invasive capacity for cultured human epithelial cells. This study provides genetic and functional evidence supporting the conclusion that protein $F$ is capable of mediating entry of S. pyogenes into HeLa cells. Using Tn916 insertion mutagenesis or an isogenic S. pyogenes strain with a defined mutation in the gene encoding protein $F$ (prtf), it was observed that the invasive capacity was affected by the levels of surface-exposed protein $F$, but not by those of $M$ protein. In addition, heterologous expression of protein $F$ on Enterococcus faecalis conferred upon the bacteria an efficient invasive phenotype. Several assays demonstrated that both the fibronectin-binding domains of protein F, UR and RD2, were involved in host-cell invasion. In addition, coinfection experiments of HeLa cells with $S$. pyogenes and an Escherichia coli K-12 strain expressing an afimbrial adhesin AFA-I showed that the uptake of $S$. pyogenes did not permit internalization of the $E$. coli cells.
\end{abstract}

Keywords: streptococcal infection, invasion, transposon mutagenesis, virulence

\section{INTRODUCTION}

The Gram-positive bacterium Streptococcus pyogenes (group A streptococcus) is one of the most versatile human pathogens with regard to the number of different tissues it can infect and the wide range of different diseases it can cause, including suppurative infections of the throat (pharyngitis) and of the skin and soft tissues (impetigo, erysipelas, cellulitis, necrotizing fasciitis and myositis). Systemic complications can accompany infection of the skin (scarlet fever, toxic-shock-like syndrome and sepsis) (Bisno \& Stevens, 1996) and a role for the host immune response to streptococcal antigens has been implicated in rheumatic fever. These diseases result from the ability of $S$. pyogenes to adhere to and colonize on epithelial cells of the pharyngeal mucosa or the skin. Although $S$. pyogenes has generally been considered an extracellular pathogen, it has recently been shown that streptococci can penetrate into several types of cultured human epithelial cells (LaPenta et al., 1994; Greco et al., 1995; Schranger et al., 1996; Molinari et al., 1997).

†Present address: Department of Microbiology, School of Pharmaceutical Sciences, Kitasato University, 5-9-1 Shirokane, Minato-ku, Tokyo 108-8641, Japan.
The initial interaction between bacteria and host cells is mediated by bacterial surface components (adhesins/ invasins) and specific receptors on the surface of the host cells. In S. pyogenes, several surface components have been shown to participate in the interaction with eukaryotic cells. These include $\mathrm{M}$ protein for epidermal keratinocytes (Okada et al., 1994) and cultured HEp-2 cells (Wang \& Stinson, 1994), and the fibronectinbinding proteins for respiratory epithelial cells (Hanski \& Caparon, 1992; Talay et al., 1992) as well as Langerhans' cells (Okada et al., 1994). It is known that the structure of these streptococcal proteins is analogous to that of internalin A, an invasin protein of Listeria monocytogenes, which contains tandem repeats and is anchored to the cell wall peptidoglycan by covalent linkage via the threonine residue of the conserved LPXTG motif (Gaillard et al., 1991). More recently, the involvement of protein SfbI, a protein related to protein $F$ capable of binding to fibronectin, has been implicated in the internalization of the streptococcus by epithelial cells (Molinari et al., 1997).

In $S$. pyogenes, perhaps the best-characterized fibronectin-binding molecules are the closely related proteins protein F (Hanski \& Caparon, 1992) and SfbI (Talay et 
al., 1991, 1992). These proteins bind fibronectin when expressed in Escherichia coli (Hanski \& Caparon, 1992; Talay et al., 1992), can inhibit the binding of fibronectin to intact streptococcal cells (Hanski \& Caparon, 1992; Talay et al., 1992) and can inhibit the adherence of streptococci to several types of epithelial cells (Talay et al., 1992). Insertional inactivation of the gene encoding protein $\mathrm{F}(p r t F)$ generated mutants of $S$. pyogenes that were completely deficient in binding fibronectin and in their ability to adhere to respiratory epithelial cells (Hanski \& Caparon, 1992; Talay et al., 1992). Previous studies have shown that protein $\mathrm{F}$ contains two distinct fibronectin-binding domains, a tandem repetitive domain (RD2) and a domain immediately $\mathrm{N}$-terminal to the repetitive domain (UR) (Sela et al., 1994; Ozeri et al., 1996). The minimal functional binding unit of the RD2 repeat domain consists of 44 amino acids located at the junction of two adjacent sequence repeats and is flanked by an 'MGGQSES' motif. This functional unit recognizes the $\mathrm{N}$-terminal fibrin-binding domain of fibronectin (Ozeri et al., 1996). UR contains 49 amino acids and consists of the 43 amino acids located immediately $\mathrm{N}$-terminal to RD2 and the first six amino acids from the first repeat of RD2. This domain binds to a large region of fibronectin that includes both the $\mathrm{N}$ terminal fibrin and adjacent collagen-binding domains (Ozeri et al., 1996). Although UR binds fibronectin with high affinity and is the dominant domain for the binding of soluble fibronectin to protein F (Ozeri et al., 1996), both domains are required for efficient binding to the extracellular matrix (Ozeri et al., 1996) and multimeric fibronectin fibrils (Okada et al., 1997). These fibronectin-binding domains are also involved in streptococcal adherence mediated by protein $\mathrm{F}$ to host cells (Talay et al., 1992; Ozeri et al., 1996; Okada et al., 1997).

We undertook to investigate by transposon mutagenesis the bacterial component(s) involved in host-cell invasion by virulent $S$. pyogenes, and found that less invasive mutants had decreased expression of protein $F$ on their surface compared with the parental strain. Furthermore, in contrast to the wild-type parent strain, an isogenic prtF mutant showed greatly diminished invasiveness for HeLa cells. In this study, we provide direct genetic evidence that protein $\mathrm{F}$ is a crucial surface component of $S$. pyogenes required for invasion of cultured epithelial cells, and show that HeLa cells coinfected with $S$. pyogenes and non-invasive $E$. coli permit only the internalization of $S$. pyogenes.

\section{METHODS}

Bacterial strains and growth conditions. S. pyogenes JRS4 produces a serotype $6 \mathrm{M}$ protein and is a spontaneous streptomycin-resistant derivative of D471 obtained from the Rockefeller University collection (Scott et al., 1986). JRS145 was derived from JRS4 by insertional inactivation of the gene emm6.1, which encodes M6 protein (Caparon et al., 1992). Protein $\mathrm{F}$ is a major fibronectin-binding protein of JRS4 (Hanski \& Caparon, 1992). Insertional inactivation of prtF in JRS4 and JRS145 generated SAM1 and SAM2, respectively, which were completely deficient in binding fibronectin
(Hanski \& Caparon, 1992). OGIX is a strain of Enterococcus faecalis (Ike et al., 1983). S. pyogenes and Ent. faecalis were cultured in Todd-Hewitt medium (Difco) supplemented with $0.2 \%$ yeast extract (THY medium). For coinfection experiments, E. coli HB101 carrying pIL14 which encodes the afimbrial adhesin (AFA-I) (Labigne-Roussel et al., 1984), Salmonella typhimurium SL1344 (Hoiseth \& Stocker, 1981) and Yersinia pseudotuberculosis YPIII (Bolin et al., 1982) were used. E. coli was grown in Luria-Bertani (LB) broth at $37^{\circ} \mathrm{C}$ with agitation. Salm. typhimurium was grown under low-oxygen conditions to obtain the efficient invasive phenotype (Lee \& Falkow, 1990). Cultures of Y. pseudotuberculosis were grown in LB broth with agitation at $28^{\circ} \mathrm{C}$ overnight.

Plasmid construction. Replacement of a $1.1 \mathrm{~kb}$ Apal-NcoI fragment of the $E$. coli-streptococcus shuttle vector pLZ12Km (Hanski et al., 1992) with a 219 bp Apal-PvuII fragment of pBlueScript II-KS(+) (Stratagene), which contains multicloning sites, generated pLZ12-Km2. Plasmid pLZ12-Km2 was digested with EcoRI and $\mathrm{Xhol}$ and ligated to the $2.9 \mathrm{~kb}$ EcoRI and SalI fragment from pPTF5 (containing the complete $p r t F$ gene) (Hanski \& Caparon, 1992) to generate plasmid pNSP80.

Transposon mutagenesis. Transposon mutagenesis was achieved by conjugation of $\operatorname{Tn} 916$ from Ent. faecalis CG110 to S. pyogenes JRS4, as described previously (Caparon \& Scott, 1991). Transconjugants were selected by growth on THY agar containing tetracycline $\left(5 \mu \mathrm{g} \mathrm{ml}^{-1}\right)$ and streptomycin $(1000 \mu \mathrm{g}$ $\mathrm{ml}^{-1}$ ) and were confirmed to be $S$. pyogenes by $\beta$-haemolysis on sheep blood agar.

Purification of fusion proteins containing the fibronectinbinding domain(s) of protein $F$ and antibody preparation. The fusion proteins were purified from SG13009(pREP4) (Qiagen) containing the appropriate plasmid including pUR-4 (UR), pRD-2 (RD2) and pPTF54 (UR plus five repeats of RD2) as described previously (Hanski et al., 1995). To obtain polyclonal antibodies against the fibronectin-binding domains, rabbits were immunized with the purified fusion proteins containing either UR or RD2. The IgG fraction was separated from sera by affinity chromatography on a protein A-Sepharose column (Pharmacia). The specificity of each antibody was confirmed by Western blotting.

Adherence and internalization assays. Since examination of S. pyogenes JRS4 for its invasiveness for A549, HeLa, HEp-2, $\mathrm{HaCaT}$ and MDCK cells using a gentamicin protection assay showed that the number of bacteria internalized into $\mathrm{HeLa}$ cells was higher than the other epithelial cells (data not shown), HeLa cells were used for the adherence and internalization assays. HeLa cells were cultured in Minimal Eagle's Medium (MEM) containing 10\% foetal calf serum (FCS) without antibiotics in a humidified atmosphere of $5 \% \mathrm{CO}_{2}$ and $95 \%$ air at $37^{\circ} \mathrm{C}$. For adherence assays, bacteria were grown at $37^{\circ} \mathrm{C}$ in THY medium overnight and diluted in MEM to a concentration of $1 \times 10^{7}$ bacteria $\mathrm{ml}^{-1}$. A $100 \mu \mathrm{l}$ aliquot of bacterial suspension was added to cultured cells grown in 24-well plates at a density of $2 \times 10^{5}$ cells per well. After $2 \mathrm{~h}$ incubation at $37^{\circ} \mathrm{C}$ in $5 \% \mathrm{CO}_{2}$ to allow bacterial adherence, the cells were washed five times and analysed by staining with $0.1 \%$ crystal violet and light microscopy as described by Okada et al. (1994). Internalization assays were performed in a similar fashion to adherence assays, except that after the $2 \mathrm{~h}$ incubation, the monolayers were washed twice, and overlaid with fresh MEM containing gentamicin $(200 \mu \mathrm{g}$ $\mathrm{ml}^{-1}$ ) to kill extracellular bacteria. The samples were further incubated at $37^{\circ} \mathrm{C}$ for $2 \mathrm{~h}$ in $5 \% \mathrm{CO}_{2}$. The cells were then washed three times and lysed by adding $500 \mu \mathrm{l}$ cold distilled water. Viable bacteria released from the cells were counted on 
THY agar plates. In some experiments, bacteria were centrifuged onto cells at $380 \mathrm{~g}$ for $10 \mathrm{~min}$ and then assayed for ability to escape gentamicin killing as described above.

For inhibition assays, HeLa cell monolayers were preincubated with the purified protein containing various concentrations of either UR, RD2 or UR plus five RD2 repeats at $37^{\circ} \mathrm{C}$ for $1 \mathrm{~h}$ before the infection. Inhibitions with a rabbit polyclonal antibody specific for the fibronectin-binding domain of protein $\mathrm{F}$ were performed by incubation of $S$. pyogenes JRS145 with antibody $\left(25 \mu \mathrm{g} \mathrm{ml}^{-1}\right)$ at $37^{\circ} \mathrm{C}$ for $1 \mathrm{~h}$ prior to infection.

For screening of invasion-deficient mutants from the bank of Tn916 insertion mutants, the mutants were grown overnight in THY medium containing tetracycline $\left(5 \mu \mathrm{g} \mathrm{ml}^{-1}\right)$ and streptomycin $\left(1000 \mu \mathrm{g} \mathrm{ml}^{-1}\right)$ in 96-well microtitre plates. A $10 \mu$ l volume of each bacterial culture was added to HeLa cells grown in 96-well microtitre plates in a volume of $200 \mu \mathrm{MEM}$ per well. The gentamicin protection assay was performed as described above. Cells were lysed by adding $100 \mu \mathrm{l}$ cold distilled water and a portion of $10 \mu \mathrm{l}$ was plated onto THY agar. The number of viable bacteria was scored after overnight incubation at $37^{\circ} \mathrm{C}$. Mutants for which bacterial growth was markedly reduced were further assayed for entry by quantitative standard internalization assay described above.

DNA sequencing strategy. The Tn916-flanking regions from Tn916 mutants were amplified by using an inverse PCR method as described by Lyristis et al. (1994). DNA fragments amplified were sequenced by the dideoxy chain-termination method with a Sequenase version 2.0 DNA sequencing kit (United States Biochemicals).

Quantitative measurements of protein $F$ expression on the bacterial surface. Bacterial cultures were spotted on a nitrocellulose filter laid on a THY agar plate and incubated at $37^{\circ} \mathrm{C}$ for $18 \mathrm{~h}$. The filter was blocked by washing for $30 \mathrm{~min}$ in $5 \%$ skim milk in PBS containing $0.05 \%$ sodium azide and then incubated with anti-RD2 domain antibody at room temperature for $2 \mathrm{~h}$. After washing three times with PBS containing $0.05 \%$ Tween 20 (PBS-T), the blots were incubated with alkaline-phosphatase-conjugated goat anti-rabbit IgG antiserum (Sigma) at room temperature for $3 \mathrm{~h}$. The reaction was detected by alkaline phosphatase buffer $(100 \mathrm{mM} \mathrm{NaCl}$, $5 \mathrm{mM} \mathrm{MgCl}, 100 \mathrm{mM}$ Tris/HCl, $\mathrm{pH} 9.5$ ) containing nitroblue tetrazolium $\left(300 \mu \mathrm{g} \mathrm{ml}^{-1}\right)$ and bromochloroindolyl phosphate $\left(150 \mu \mathrm{g} \mathrm{ml}^{-1}\right)$. Data were processed by using a Macintosh-based image analysis program (NIH image).

Coinfection experiments. HeLa cells grown in 24-well plates were inoculated simultaneously with $1 \times 10^{7}$ E. coli HB101 harbouring pIL14 and either S. pyogenes JRS145, Salm. typhimurium or Y. pseudotuberculosis, centrifuged at $380 \mathrm{~g}$ for $10 \mathrm{~min}$ and incubated at $37^{\circ} \mathrm{C}$ for $1 \mathrm{~h}$ in $5 \% \mathrm{CO}_{2}$. The cells were washed and subjected to the gentamicin protection assay to recover intracellular bacteria. The number of gentamicin-resistant bacteria was estimated by colony counting after overnight growth on agar plates; LB agar containing ampicillin $\left(250 \mu \mathrm{g} \mathrm{ml}^{-1}\right)$ was used for E. coli strain HB101(pIL14).

\section{RESULTS}

\section{Less invasive mutants of $S$. pyogenes have decreased levels of surface-expressed protein $F$}

To identify the genetic locus of $S$. pyogenes M6 serotype strain JRS4 required for the invasion of epithelial cells, a random insertion mutagenesis with the conjugative
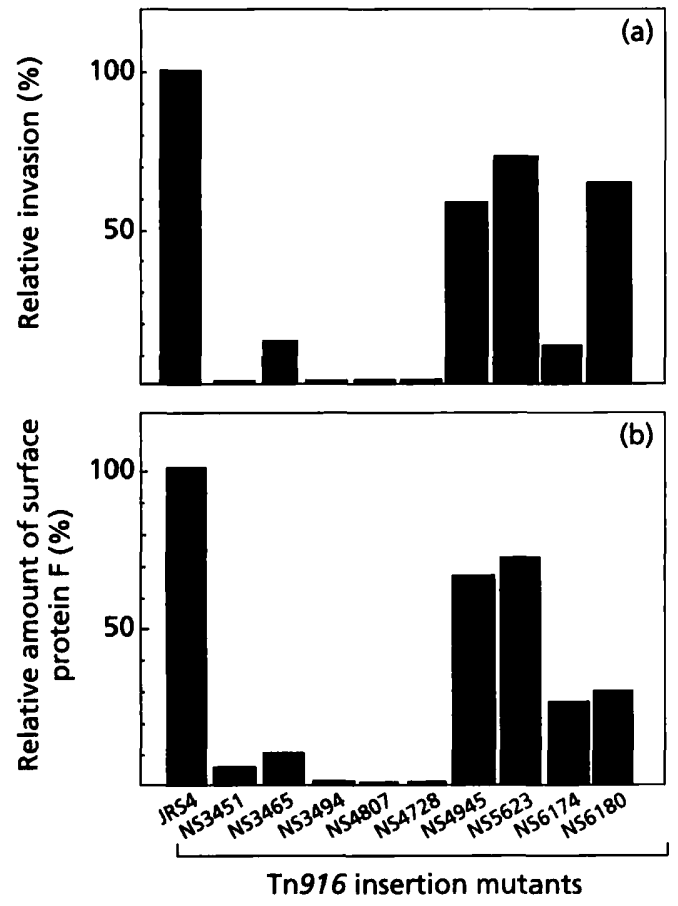

Fig. 1. Surface expression of protein $F$ affects entry of $S$. pyogenes into cultured epithelial cells. (a) Internalization assays for Tn916 mutants were performed as described in Methods. When a total number of $1 \times 10^{6}$ strain JRS4 was added to HeLa cell monolayers, $3-5 \%$ of bacteria were recovered from infected cells after treatment with gentamicin for $2 \mathrm{~h}$, which is given the value $100 \%$. Data represent the mean of triplicate determinations, which differed by $\leqslant 10 \%$ from the mean value. (b) Amount of protein $F$ expressed on the bacterial surface was determined by immunostaining of live bacteria using anti-RD2 domain antibody: $100 \%$ represents the amount of protein $F$ expressed by JRS4. Data represent the mean of triplicate determinants, which differed by $\leqslant 10 \%$ from the mean value. Note that the amounts of $M$ protein expressed from each of the mutants as determined by immunostaining of live bacteria using anti-M6 specific antibody were shown to be less than $\pm 5 \%$ different from that of JRS4. The growth rate of each mutant in MEM supplemented with $10 \%$ FCS as judged by turbidity measured at $600 \mathrm{~nm}$ was also essentially the same.

transposon $\operatorname{Tn} 916$ was performed and 5387 insertion mutants were screened by a simplified gentamicin protection assay for their ability to enter HeLa cells. Nine of the resultant mutants were identified with reduced invasive capacity, which was $1-54 \%$ of that of JRS4 (Fig. 1a). To investigate the cause of the reduced invasiveness, each of the Tn916-flanking DNA sequences of these mutants was determined and the sites of Tn916 insertions on its chromosome were estimated by using the database of the $S$. pyogenes genome sequence (University of Oklahoma's Advanced Center for Genome Technology). The insertion site for each mutant was assigned as follows: NS3451 possessed Tn916 within a region homologous to the $\mathrm{ABC}$ transporter operon of Bacillus subtilis (accession number P54719). NS3494 and NS6174 possessed Tn916 in a region homologous to the spoVM operon of Bacillus subtilis (Levin et al., 1993). NS4807 possessed Tn916 in an 
unknown gene encoding an 88 aa protein (accession number U07341). NS4728 possessed Tn916 in the vicinity of a gene encoding a protein homologous to the $\alpha$-haemolysin of Aeromonas hydrophila (accession number L36462). NS5623 possessed Tn916 in a gene encoding a protein similar to the Rgg protein of Streptococcus gordonii, known as a positive regulator for glucosyltransferase (Sulavik et al., 1992). NS6180 possessed Tn916 in between two genes within an operon associated with the biosynthesis of D-alanyl-lipoteichoic acid of B. subtilis (Perego et al., 1995). Tn916 insertion regions from NS3465 and NS4945 were not homologous to any sequences in the database. Although the precise effect of each mutation on the invasiveness of $S$. pyogenes was still unclear, some surface proteins may be important for determining the level of invasiveness.

To investigate whether the reduced invasiveness of the Tn916 insertion mutants resulted from a defect in their ability to adhere to epithelial cells, the cell-binding capacity to $\mathrm{HeLa}$ cell monolayers was measured. Although the adherence ability of each mutant as judged by enumeration of numbers of bacteria associated with the HeLa cells was essentially the same as that of JRS4, the mutant bacteria were distributed more evenly on the cell surface than JRS4. JRS4 bacteria attached to HeLa cells frequently formed aggregates on the cell surface, suggesting that the Tn916 insertion mutations resulted in some change in the surface property of the streptococci (data not shown). We thus examined the mutants for their surface expression of protein $F$ and $M$ protein, since they are the major adhesins on strain JRS4 (Hanski \& Caparon, 1992; Okada et al., 1994). The mutants grown on a nitrocellulose membrane were immunostained with either a rabbit anti-RD2 antibody, an antiserum specific for the fibronectin-binding domain of protein $\mathrm{F}$, or a rabbit anti-M6 protein antiserum, and the amount of each protein was quantified. Whereas levels of the surface expression of $M$ protein of the mutants were similar to that of JRS4 (data not shown), the expression of protein $\mathrm{F}$ of the mutants was reduced significantly compared with that of JRS4 (Fig. 1). Importantly, the extent of the decreased expression of protein $\mathrm{F}$ showed good agreement with the decreased invasiveness of each mutant for HeLa cells (Fig. 1), suggesting that the amount of protein $\mathrm{F}$ on the bacterial surface was related to the invasive capacity of $S$. pyogenes.

\section{Protein $F$ is required for streptococcal invasion}

To clarify the role of protein $F$ in the expression of invasiveness of $S$. pyogenes, we examined a set of isogenic $S$. pyogenes strains with defined mutations in the genes which encode protein $F$ and $M$ protein for their ability to bind to HeLa cells prior to invasion. Wild-type strain JRS4 $\left(\mathrm{M}^{+}, \mathrm{F}^{+}\right)$bound $90 \%$ of $\mathrm{HeLa}$ cells. Strains JRS145 $\left(\mathrm{M}^{-}, \mathrm{F}^{+}\right)$and SAM1 $\left(\mathrm{M}^{+}, \mathrm{F}^{-}\right)$ bound $81 \%$ of that bound by JRS4 strain when assayed under identical conditions. By contrast, double-mutant strain SAM2 $\left(\mathrm{M}^{-}, \mathrm{F}^{-}\right)$showed only $27 \%$ adherence

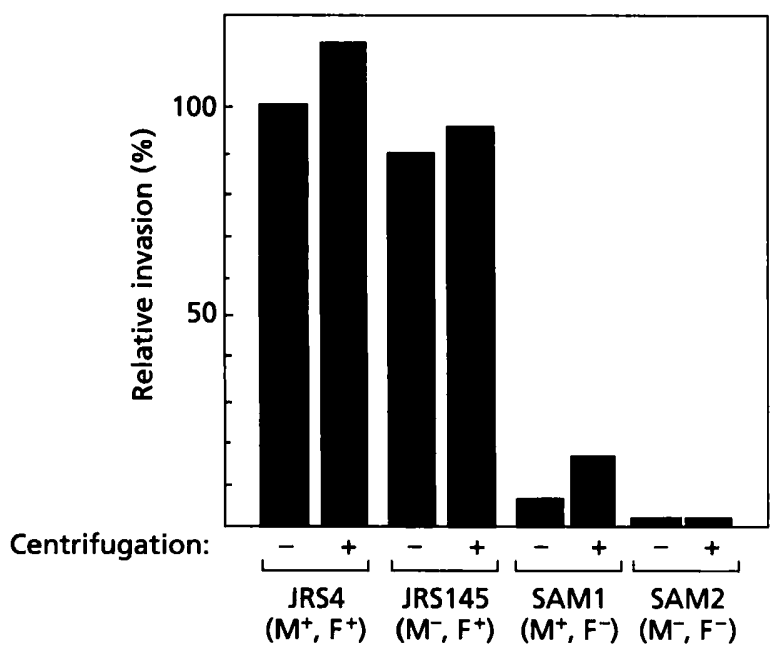

Fig. 2. Efficient entry of $S$. pyogenes into HeLa cells requires expression of protein $F$. Invasiveness of isogenic $S$. pyogenes strains, JRS4 $\left(\mathrm{M}^{+}, \mathrm{F}^{+}\right)$, JRS145 $\left(\mathrm{M}^{-}, \mathrm{F}^{+}\right)$, SAM1 $\left(\mathrm{M}^{+}, \mathrm{F}^{-}\right)$and SAM2 $\left(\mathrm{M}^{-}, \mathrm{F}^{-}\right)$was determined by gentamicin protection assays with $(+)$ or without $(-)$ centrifugation prior to infection (see Methods for details). Data represent the mean of triplicate determinants, which differed by $\leqslant 10 \%$ from the mean value.

compared with the parental strain, confirming previous studies that $M$ protein and protein $F$ served as the major streptococcal adhesions for epithelial cells (Hanski \& Caparon, 1992; Okada et al., 1994). Each of the mutant $S$. pyogenes strains was then measured for its invasive capacity by the gentamicin protection assay. As shown in Fig. 2, the invasiveness of the F-deficient mutant SAM1 decreased to $6 \%$ of the wild-type (JRS4) level. By contrast, the M-deficient mutant JRS145 showed $90 \%$ invasiveness compared with JRS4 (Fig. 2). The invasiveness of the double mutant SAM2 was only $2 \%$ of the wild-type level (Fig. 2). Upon mechanical enhancement of attachment of streptococci to the HeLa cell monolayers using centrifugation, the invasiveness of SAM1 increased to $18 \%$ of that of the wild-type strain, whereas the invasiveness of SAM2 remained at $2 \%$ (Fig. 2). Next, the number of internalized bacteria within HeLa cells was measured at different multiplicities of infection with JRS145 and SAM2. As shown in Fig. 3(b), the number of internalized JRS145 bacteria increased with the infecting dose up to $1 \times 10^{7}$ bacteria per well, whereas the number of internalized SAM2 cells did not increase at all. The results of the series of experiments indicated that although adherence directed by protein $\mathrm{F}$ could directly promote uptake of streptococci by HeLa cells, neither the bacterial binding mediated by $M$ protein nor mechanical contact was involved in the invasiveness.

To better understand the role of protein $F$ in the invasiveness of streptococci, we introduced plasmid pNSP80, which contains the complete prtF gene, into Ent. faecalis strain OG1X, which lacks a prtF-related gene (Hanski et al., 1992), and the resulting Ent. faecalis transformant OGIX(pNSP80) was examined for its adhesive and invasive capacity for HeLa cells. Strain 
(a)

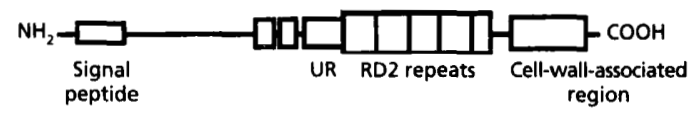

(b)

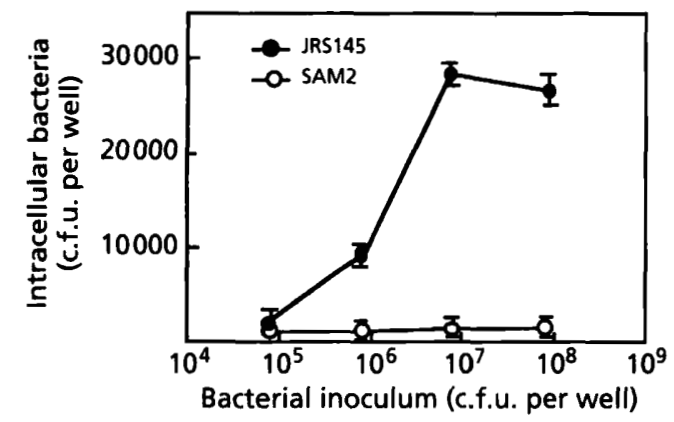

(c)

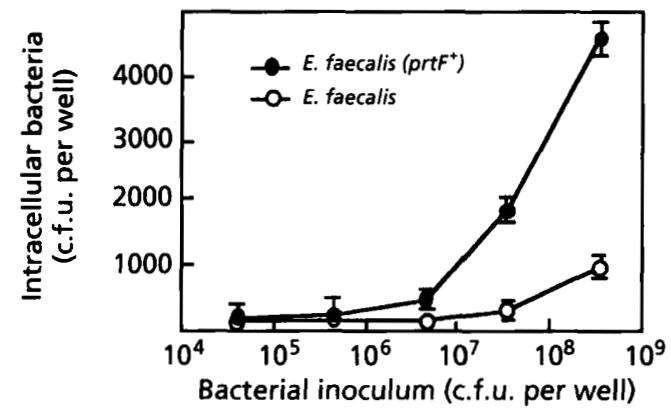

Fig. 3. Protein $F$ mediates entry of $S$. pyogenes into cultured epithelial cells. Hela cell monolayers were infected with increased numbers of various Ent. faecalis and $S$. pyogenes strains, and subjected to the gentamicin protection assays. (a) Structure of protein F (Sela et al., 1994; Ozeri et al., 1996). (b) Invasiveness of JRS145 and SAM2 at various infection dosages. (c) Invasiveness of Ent. faecalis OGIX harbouring pNSP80 which encodes protein $F$ and OGIX strain harbouring the vector plasmid $\mathrm{pLZ12}-\mathrm{Km} 2$. Under the same conditions, the level of JRS145 invasiveness was similar to that presented in (b). Data represent the mean of triplicate samples from duplicate experiments and standard error of the mean.

OGIX(pNSP80) showed increased binding ( $32 \%$ of HeLa cells) compared with OGIX(pLZ12-Km2: vector only) which did not bind at detectable levels to HeLa cells. The invasiveness of OGIX(pNSP80) was also increased compared with that of OGIX (pLZ12-Km2) (Fig. 3c). Interestingly, the invasive efficiency of OGIX(pNSP80) was significantly lower than that of $S$. pyogenes; invasiveness of OGIX(pNSP80) at an inoculum of $1 \times 10^{7}$ was only $15 \%$ of the JRS145 level (data not shown). Since the level of protein $\mathrm{F}$ expressed on the surface of Ent. faecalis has been shown to be less than that in S. pyogenes strains (Hanski et al., 1992), we measured the level of protein $\mathrm{F}$ expressed by Ent. faecalis OGIX(pNSP80) by immunostaining with anti-RD2 antibody. The results showed that the protein $F$ level on OG1X(pNSP80) was $18 \%$ of that on JRS145, consistent with the low invasiveness of the Ent. faecalis strain. Based on all the above results, we concluded that protein
F plays a major role in facilitating the invasiveness of $S$. pyogenes.

\section{Two distinct fibronectin-binding domains of protein F, UR and RD2, are essential for invasion}

Previous studies demonstrated that protein F contained two distinct fibronectin-binding domains, termed UR and RD2 (Sela et al., 1994; Ozeri et al., 1996), that are responsible for bacterial adhesion to epithelial cells (Fig. 3a). To determine which of the fibronectin-binding domains was involved in streptococcal invasion of cultured epithelial cells, purified proteins containing either UR, RD2, or UR plus five RD2 repeats were tested for their ability to inhibit competitively the invasion of HeLa cells by $S$. pyogenes. Pretreatment with the purified protein containing UR plus five RD2 repeats at $1000 \mathrm{nM}$ reduced the invasiveness of JRS145 by $72 \%$, whereas purified proteins containing either UR or RD2 alone inhibited the invasiveness by $51 \%$ and $60 \%$, respectively (Fig. 4a). To confirm this, we produced polyclonal antibodies against each of UR and RD2 domains and examined their abilities to block bacterial entry into HeLa cells. Each of anti-UR and anti-RD2 antibodies at $25 \mu \mathrm{g} \mathrm{ml}^{-1}$ inhibited the entry of JRS145 by $10 \%$ and $38 \%$, respectively, whereas the mixture of the same amounts of anti-UR and anti-RD2 antibodies inhibited the entry by $78 \%$ (Fig. 4b), indicating that the two domains participate in the invasion of epithelial cells.

\section{Streptococcal invasion strategy}

To assess the internalization strategies adopted by $S$. pyogenes, HeLa cell monolayers were infected with JRS145 and the non-invasive E. coli strain HB101 harbouring pIL14, which encodes the afimbrial adhesin AFA-I, and assayed for the uptake of HB101(pIL14). As shown in Table 1, uptake of HB101(pIL14) by JRS145 was not significantly promoted as compared with that by Salmonella; rather the efficiency of uptake of HB101(pIL14) by JRS145 was similar to that by Yersinia.

\section{DISCUSSION}

Recent studies have indicated that, although S. pyogenes has long been considered a highly adhesive extracellular pathogen, the bacteria can also invade various human epithelial cells (LaPenta et al., 1994; Greco et al., 1995; Schranger et al., 1996; Molinari et al., 1997). However, neither the direct genetic evidence nor the underlying invasive strategy leading to uptake of streptococci by mammalian cells has been reported. In this study, we have provided genetic evidence that the ability of $S$. pyogenes to enter epithelial cells is mediated by protein F. These conclusions were drawn from the following results: (i) the amounts of protein $\mathrm{F}$ expressed on $S$. pyogenes can affect the invasion efficiency; (ii) the inactivation of a $p r t F$ gene from $S$. pyogenes results in a remarkable decrease in invasiveness; (iii) the heterologous expression of protein $F$ in Ent. faecalis renders 

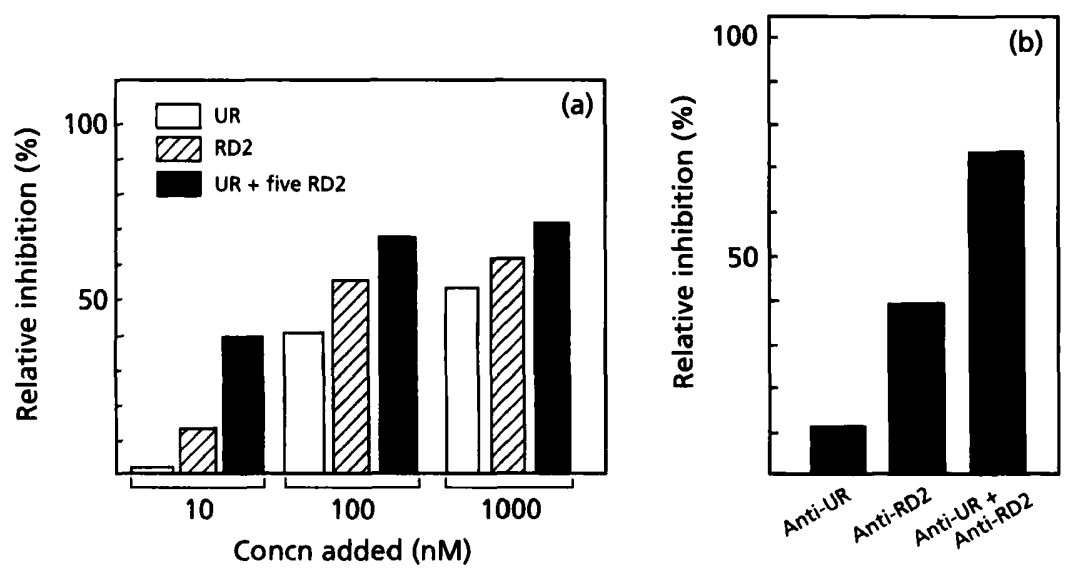

Fig. 4. Both fibronectin-binding domains of protein $F$ are required for efficient invasion by $S$. pyogenes. Inhibition by purified proteins containing fibronectin-binding domains of protein $F(a)$ or antibody specific for either UR or RD2 domain (b) is shown. (a) Semiconfluent HeLa cell monolayers were pretreated with various concentrations of purified protein and then incubated for $2 \mathrm{~h}$ at $37^{\circ} \mathrm{C}$ with $1 \times 10^{6}$ bacteria. For the control, BSA (1000 nM) was used. (b) Antibodies at $25 \mu \mathrm{g} \mathrm{ml}^{-1}$ were preincubated with bacteria at $37^{\circ} \mathrm{C}$ for $1 \mathrm{~h}$ prior to infection. Purified IgG from normal rabbit serum at the same concentration was used as a control. The number of intracellular bacteria was quantified by gentamicin protection assay. The data are expressed as the percentage of inhibition relative to the control experiments. Data represent the mean of triplicate determinants, which differed by $\leqslant 5 \%$ from the mean value.

Table 1. Coinfection of HeLa cells with S. pyogenes JRS145 and AFA-I expressing E. coli

Both the strain indicated and $1 \times 10^{7}$ E. coli HB101(pIL14) were added to the same wells and centrifuged at $380 \times g$ for $10 \mathrm{~min}$. Samples were incubated for $1 \mathrm{~h}$ at $37^{\circ} \mathrm{C}$ in $5 \% \mathrm{CO}_{2}$ and then were incubated for a further $2 \mathrm{~h}$ at the presence of gentamicin. The number of gentamicin-resistant bacteria was determined by counting viable cells using selective plates. Data represent the means of triplicate samples from duplicated assays.

\begin{tabular}{|c|c|c|c|}
\hline \multirow[t]{2}{*}{ Strain } & \multirow{2}{*}{$\begin{array}{l}\text { Inoculum } \\
\text { (c.f.u. per } \\
\text { well) }\end{array}$} & \multicolumn{2}{|c|}{ Intracellular survival (c.f.u. per well) } \\
\hline & & $\begin{array}{l}\text { Bacteria } \\
\text { recovered }\end{array}$ & $\begin{array}{c}\text { HB101(pIL14) } \\
\text { when } \\
\text { coinfected }\end{array}$ \\
\hline \multirow[t]{3}{*}{ S. pyogenes JRS145 } & $2.0 \times 10^{5}$ & $2.6 \times 10^{2}$ & $4 \cdot 1 \times 10^{1}$ \\
\hline & $2 \cdot 0 \times 10^{6}$ & $1 \cdot 1 \times 10^{4}$ & $4.5 \times 10^{1}$ \\
\hline & $2 \cdot 0 \times 10^{7}$ & $5 \cdot 3 \times 10^{4}$ & $4.0 \times 10^{1}$ \\
\hline Salm. typhimurium & $2 \cdot 1 \times 10^{7}$ & $2.6 \times 10^{4}$ & $2 \cdot 5 \times 10^{3}$ \\
\hline Y. pseudotuberculosis & $2.6 \times 10^{6}$ & $6.0 \times 10^{4}$ & $4.0 \times 10^{1}$ \\
\hline E. coli HB101(pIL14) & $1.0 \times 10^{7}$ & $1.9 \times 10^{1}$ & \\
\hline
\end{tabular}

bacteria invasive; and (iv) the invasive capacity of $S$. pyogenes is inhibited by the addition of purified protein F portions or specific antibodies.

In this study, we isolated nine mutants of $S$. pyogenes with reduced invasiveness by using random Tn916 insertion mutagenesis and noted that the $\operatorname{Tn} 916$ insertion mutants were all significantly decreased in the expression of protein $F$. Importantly, the levels of $M$ protein, another major surface protein involved in adherence to epithelial cells, were not affected by the Tn916 insertions at all. Rather, the decreased levels of invasiveness showed good correlation with the surface levels of protein $\mathrm{F}$. The defined prtF mutant strains of $S$. pyogenes clearly demonstrated that the absence of prtF affects invasive capacity. Furthermore, the heterologous expression of protein $\mathrm{F}$ in Ent. faecalis can confer on the bacteria the ability to invade cultured epithelial cells. The induced invasive capacity in Ent. faecalis was less than $15 \%$ of the $S$. pyogenes level. It has been shown that the heterologous expression of protein $\mathrm{F}$ on Ent. faecalis was weaker than that on S. pyogenes (Hanski et al., 1992); the observed decrease in the invasiveness of Ent. faecalis is consistent with the less efficient expression of the protein $\mathrm{F}$ on the surface.

The genes that encode fibronectin-binding proteins, known as the protein $\mathrm{F} / \mathrm{SfbI}$ family, are widely distributed among diverse isolates of $S$. pyogenes, in which the two distinct fibronectin-binding domains are highly conserved (Talay et al., 1994; Natanson et al., 1995). DNA sequencing analysis has revealed that whereas SfbI 
protein contains only four RD2-type repeats, the amino acid sequences of the fibronectin-binding domains of SfbI are similar to that of protein F, namely UR and RD2 (Talay et al., 1992; Sela et al., 1994). These fibronectinbinding domains of both proteins have been shown to be essential for binding to fibronectin and adherence to host cells (Talay et al., 1992; Sela et al., 1994; Ozeri et al., 1996; Okada et al., 1997). Recently, Molinari et al. (1997) reported that Sfbl mediates streptococcal attachment to, and internalization by, cultured HEp-2 cells via fibronectin-binding domains. In the present study we found that either purified UR or RD2 portions of protein $F$ or antibodies specific for UR and RD2 could inhibit the entry of bacteria into cultured epithelial cells. The fact that streptococci expressing either UR or RD2, or both, on their surface possess a potency to adhere to, as well as to invade mammalian cells argues strongly that a direct link of streptococci to the host-cell receptor is involved in uptake of bacteria.

Since protein $\mathrm{F}$ binds fibronectin at high affinity, it would be reasonable to speculate that a cellular fibronectin receptor such as $\alpha_{5} \beta_{1}$ integrin serves as a receptor for protein $\mathrm{F}$, in which fibronectin may be required as the adapter for connection between protein $\mathrm{F}$ and the integrin. Our preliminary data support this hypothesis, since invasive efficiency of $S$. pyogenes was significantly increased for CHO-HFR5 cells (Watarai et al., 1996), a high $\alpha_{5} \beta_{1}$-integrin-expressing $\mathrm{CHO}$ cell line, compared with that for the parental $\mathrm{CHO}$ cells. Although no direct evidence supporting our hypothesis has been obtained, it is most likely that the ability of protein $\mathrm{F}$ to bind fibronectin plays a crucial role in promoting the internalization of $S$. pyogenes. In any case, further studies must be required for elucidating the mechanisms for streptococcal invasion of epithelial cells.

Although none of the Tn916 insertion sites on the chromosome of the mutant was in the prtF region, the decrease in the protein $F$ expression on the bacterial surface appears to have arisen from different defects in each mutant. For example, protein $\mathrm{F}$ secretion might be impaired in NS3451, since the Tn916 was inserted in a DNA region homologous to the $\mathrm{ABC}$ transporter operon of $B$. subtilis. An alteration on the bacterial surface might occur in NS6180, which may affect the linkage of protein $\mathrm{F}$ to the peptidoglycan in the streptococcal cell wall, since the insertion of Tn916 was located within an operon encoding genes involved in the biosynthesis of $\mathrm{D}$ alanyl-lipoteichoic acid of $B$. subtilis. Although the precise functional roles of each mutated gene in the nine Tn916 insertion mutants in terms of their expression of protein $\mathrm{F}$ remain to be elucidated, it is likely that a number of functions could directly and indirectly be involved in the surface expression of protein $F$, thereby eventually affecting the invasiveness of $S$. pyogenes.

\section{ACKNOWLEDGEMENTS}

We would like to thank Ben Adler for critical reading of this manuscript and Miki Yokota for skilled technical assistance. This work was supported by a Grant-in-Aid for Scientific Research from the Ministry of Education, Science and Culture of Japan and the 'Research for the Futures' program of the Japanese Society for the Promotion of Science.

\section{REFERENCES}

Bisno, A. L. \& Stevens, D. L. (1996). Streptococcal infections of skin and soft tissues. $N$ Engl J Med 334, 240-245.

Bolin, I., Norlander, L. \& Wolf-Watz, H. (1982). Temperatureinducible outer membrane proteins of Yersinia pseudotuberculosis and Yersinia enterocolitica are associated with the virulence plasmid. Infect Immun 37, 506-512.

Caparon, M. G. \& Scott, J. R. (1991). Genetic manipulation of the pathogenic streptococci. Methods Enzymol 204, 556-586.

Caparon, M. G., Geist, R. T., Perez-Casal, J. \& Scott, J. R. (1992). Environmental regulation of virulence in group A streptococci: transcription of the gene encoding $M$ protein is stimulated by carbon dioxide. J Bacteriol 174, 5693-5701.

Gaillard, J.-L., Berche, P., Frehel, C., Gouin, E. \& Cossart, P. (1991). Entry of $L$. monocytogenes into cells is mediated by internalin, a repeat protein reminiscent of surface antigen from gram-positive cocci. Cell 65, 1127-1141.

Greco, R., De Martino, L., Donnarumma, G., Conte, M. P., Seganti, L. \& Valenti, P. (1995). Invasion of cultured human cells by Streptococcus pyogenes. Res Microbiol 146, 551-560.

Hanski, E. \& Caparon, M. G. (1992). Protein F, a fibronectinbinding protein, is an adhesin of the group A streptococcus, Streptococcus pyogenes. Proc Natl Acad Sci USA 89, 6172-6176.

Hanski, E., Horwitz, P. A. \& Caparon, M. G. (1992). Expression of protein F, the fibronectin-binding protein of Streptococcus pyogenes JRS4, in heterologous streptococcal and enterococcal strains promotes their adherence to respiratory epithelial cells. Infect Immun 60, 5119-5125.

Hanski, E., Fogg, G., Tovi, A., Okada, N., Burstein, I. \& Caparon, M. (1995). Molecular analysis of Streptococcus pyogenes adherence. Methods Enzymol 253, 269-305.

Hoiseth, S. K. \& Stocker, B. A. (1981). Aromatic-dependent Salmonella typhimurium are non-virulent and effective as live vaccines. Nature 291, 238-239.

Ike, Y., Craig, R. A., White, A. B., Yagi, Y. \& Clewell, D. B. (1983). Modification of Streptococcus faecalis sex pheromones after acquisition of plasmid DNA. Proc Natl Acad Sci USA 80, 5369-5373.

Labigne-Roussel, A. F., Lark, D., Schoolnik, G. \& Falkow, S. (1984). Cloning and expression of an afimbrial adhesin (AFA-I) responsible for $\mathrm{P}$ blood group-independent, mannose-resistant hemagglutination from a pyelonephritic Escherichia coli strain. Infect Immun 46, 251-259.

LaPenta, D., Rubens, C., Chi, E. \& Cleary, P. P. (1994). Group A streptococci efficiently invade human respiratory epithelial cells. Proc Natl Acad Sci USA 91, 12115-12119.

Lee, C. A. \& Falkow, S. (1990). The ability of Salmonella to enter mammalian cells is affected by bacterial growth state. Proc Natl Acad Sci USA 87, 4304-4308.

Levin, P. A., Fan, N., Ricca, E., Driks, A., Losick, R. \& Cutting, 5. (1993). An unusually small gene required for sporulation by Bacillus subtilis. Mol Microbiol 9, 761-771.

Lyristis, M., Bryant, A. E., Sloan, J., Awad, M. M., Nisbet, I. T., Stevens, D. L. \& Rood, J. I. (1994). Identification and molecular analysis of a locus that regulates extracellular toxin production in Clostridium perfringens. Mol Microbiol 12, 761-777.

Molinari, G., Talay, S. R., Valentin-Weigand, P., Rohde, M. \& Chhatwal, G. S. (1997). The fibronectin-binding protein of Strep- 
tococcus pyogenes, $\mathrm{SfbI}$, is involved in the internalization of group A streptococci by epithelial cells. Infect Immun 65, 1357-1363.

Natanson, S., Sela, S., Moses, A. E., Musser, J. M., Caparon, M. G. \& Hanski, E. (1995). Distribution of fibronectin-binding proteins among group A streptococci of different M-types. J Infect Dis 171, 871-878.

Okada, N., Pentland, A., Falk, P. \& Caparon, M. (1994). M protein and protein $F$ act as important determinants of cell-specific tropism of Streptococcus pyogenes in skin tissue. J Clin Invest 94, 965-977.

Okada, N., Watarai, M., Ozeri, V., Hanski, E., Caparon, M. \& Sasakawa, C. (1997). A matrix form of fibronectin mediates enhanced binding of Streptococcus pyogenes to host tissue. J Biol Chem 272, 26978-26984.

Ozeri, V., Tovi, A., Burstein, I., Natanson-Yaron, S., Caparon, M. G., Yamada, K. M., Akiyama, S., Vlodavsky, I. \& Hanski, E. (1996). A two-domain mechanism for group A streptococcal adherence through protein $\mathrm{F}$ to the extracellular matrix. EMBO J 15, 989-998.

Perego, M., Glaser, P., Minutello, A., Strauch, M. A., Leopold, K. \& Fischer, W. (1995). Incorporation of D-alanine into lipoteichoic acid and wall teichoic acid in Bacillus subtilis. J Biol Chem 270, 15598-15606.

Schranger, H. M., Rheinwald, J. G. \& Wessels, M. R. (1996). Hyaluronic acid capsule and the role of streptococcal entry into keratinocytes in invasive skin infection. J Clin Invest 98, 1954-1958.

Scott, J. R., Guenther, P. C., Malone, L. M. \& Fischetti, V. A. (1986). Conversion of an $\mathrm{M}^{-}$group A streptococcus to $\mathrm{M}^{+}$by transfer of a plasmid containing an M6 gene. J Exp Med 164, 1641-1651.

Sela, S., Arvik, A., Burstien, I., Tovi, A., Caparon, M. G. \& Hanski, E. (1994). Protein F, an adhesin of Streptococcus pyogenes, binds fibronectin via two distinct domains. Mol Microbiol 10, 1049-1055.

Sulavik, M. C., Tardif, G. \& Clewell, D. B. (1992). Identification of a gene, $r g g$, which regulates expression of glucosyltransferase and influences the Spp phenotype of Streptococcus gordonii Challis. J Bacteriol 174, 3577-3586.

Talay, S. R., Ehrenfeld, E., Chhatwal, G. S. \& Timmis, K. N. (1991). Expression of the fibronectin-binding components of Streptococcus pyogenes in Escherichia coli demonstrates that they are proteins. Mol Microbiol 5, 1727-1734.

Talay, S. R., Valentin-Weigand, P., Jerlström, P. G., Timmis, K. N. \& Chhatwal, G. S. (1992). Fibronectin-binding protein of Streptococcus pyogenes: sequence of the binding domain involved in adherence of streptococci to epithelial cells. Infect Immun 60, 3837-3844.

Talay, S. R., Valentin-Weigand, P., Timmis, K. N. \& Chhatwal, G. S. (1994). Domain structure and conserved epitopes of $S f b$ protein, the fibronectin-binding adhesin of Streptococcus pyogenes. Mol Microbiol 13, 531-539.

Wang, J.-R. \& Stinson, M.W. (1994). M protein mediates streptococcal adhesion to HEp-2 cells. Infect Immun 62, 442-448. Watarai, M., Funato, S. \& Sasakawa, C. (1996). Interaction of Ipa proteins of Shigella flexneri with $\alpha_{5} \beta_{1}$ integrin promotes entry of the bacteria into mammalian cells. J Exp Med 183, 991-999.

Received 20 April 1998; revised 15 June 1998; accepted 24 July 1998. 